\title{
O processo criativo na construção de uma fantasia carnavalesca: em busca de uma metodologia
}

Cláudio Almeida

Mestrando, Universidade Federal do Rio de Janeiro / claudiohalmeida@gmail.com Orcid: 0000-0003-4609-4404/ lattes

Madson Oliveira

Doutor, Universidade Federal do Rio de Janeiro / madsonluis@yahoo.com.br Orcid: 0000-0003-3888-6292

Enviado: 30/05/2019 // Aceito: 14/08/2019 


\title{
O processo criativo na construção de uma fantasia carnavalesca: em busca de uma metodologia
}

\begin{abstract}
RESUMO
O desfile das escolas de samba do Rio de Janeiro é um evento sazonal e temático que é realizado por diversos profissionais ligados à criação de serviços e produtos, em função da festa. Neste artigo analisamos questões no processo criativo do carnavalesco Severo Luzardo, ao projetar uma fantasia. Assim, pretendemos ressaltar as relações entre o fazer carnavalesco e as ações de design, inserindo a prática carnavalesca como uma "forma particular de design". Para tal apresentamos um figurino carnavalesco de ala inspirado no milho e a consequente materialização deste projeto (do croqui à fantasia-protótipo pronta), tecendo paralelos com os processos metodológicos do design de moda e do design de produto. Pretendemos descortinar práticas que nos revelem processos de design e que nos levem a aproximação do carnaval à prática acadêmica do design.
\end{abstract}

Palavras-chave: carnaval. Metodologia. Fantasia carnavalesca. 


\title{
The creative process in the construction of a carnival costume: in search of a methodology
}

\begin{abstract}
The parade of samba schools in Rio de Janeiro is a seasonal and thematic party that is performed by several professionals linked to the creation of services and products, depending on the party. In this article we analyze issues in the creative process of the designer Severo Luzardo, when designing a costume. Thus, we intend to emphasize the relations between carnival and design, inserting the carnival practice as a "particular form of design". For this we present a carnival costume inspired by corn and the consequent materialization of this project (from the sketch to the fantasy-ready prototype), weaving parallels with the methodological processes of fashion design and product design. We intend to discover practices that reveal us design processes and that lead us to approach the carnival to the academic practice of design.
\end{abstract}

Keywords: carnival. Methodology. Carnival costume. 


\title{
El proceso creativo en la construcción de una fantasía de carnaval: en busca de una metodología
}

\begin{abstract}
RESUMEN
El desfile de las escuelas de samba en Río de Janeiro es un evento estacional y temático organizado por varios profesionales vinculados a la creación de servicios y productos, en función de la fiesta. En este artículo analizamos problemas en el proceso creativo del carnaval Severo Luzardo, al diseñar un disfraz. Por lo tanto, tenemos la intención de resaltar la relación entre la fabricación del carnaval y las acciones de diseño, insertando la práctica del carnaval como una "forma particular de diseño". Con este fin, presentamos un vestuario de carnaval inspirado en el maíz y la consecuente materialización de este proyecto (desde el boceto hasta el prototipo listo), tejiendo paralelos con los procesos metodológicos del diseño de moda y el diseño del producto. Tenemos la intención de descubrir prácticas que nos revelen procesos de diseño y que nos lleven a acercar el carnaval a la práctica académica del diseño.
\end{abstract}

Palabras clave: carnaval. Metodología. Fantasía de carnaval. 


\section{INTRODUÇÃO}

Este escrito é decorrente de nossa pesquisa no Programa de Pós Graduação em Design (Instituição de ensino a ser complementada na versão final, devido a normas de autoria). $\mathrm{Na}$ pesquisa de mestrado, abordamos o processo criativo envolvido no projeto das fantasias carnavalescas para o desfile das escolas de samba do Rio de Janeiro, de duas agremiações carnavalescas. Neste artigo, utilizamos como estudo de caso, uma fantasia do carnavalesco Severo Luzardo, em seu enredo "Brasil bom de boca", para o desfile do GRES União da Ilha do Governador, em 2018. O processo de criação e a metodologia projetual no desenvolvimento de fantasias carnavalescas é o objeto principal da pesquisa de mestrado, em curso atualmente no PPGD.

Ao longo deste artigo, criamos pontes e fazemos comparações com as práticas metodológicas do design, principalmente no que tange aos campos do design de moda e do design de produto. Identificamos, no desfile das escolas de samba, uma "forma particular de design" (OLIVEIRA, 2014), seja pelo processo criativo que se assemelha com o design de produto/moda ou pela metodologia projetual, na maioria dos casos. Para tanto, dialogamos com autores de campos afins, como: Felipe Ferreira com relação ao estudo para fantasias de escolas de samba; com Maria Celeste Sanches e o processo de concepção de produtos e de moda; e com Ana Maria Moraes e Sommerman em suas concepções de design.

Nesta oportunidade, usamos como estudo de caso uma fantasia de ala, num setor pontual do desfile que representa o alimento "milho", diferentemente de nossa dissertação, onde fazemos uma analogia comparativa para analisar duas fantasias diferentes, mas inspiradas no trigo. Ao final deste 
artigo refletimos sobre algumas abordagens projetuais, enquanto práticas presentes no processo criativo de carnavalescos, como ações similares realizadas por designers.

\section{A escola de samba em desfile}

Os desfiles das escolas de samba têm sua origem no Rio de Janeiro, oriundos de outras manifestações carnavalescas que serviram de alicerce para o seu surgimento (FERREIRA, 2004). Eles se organizam em torno de uma competição, onde cada escola, ainda hoje, realiza uma apresentação, de curta duração, onde há exposição de um tema através de música, sons, objetos, cores, cenários, indumentárias e alegria. Esta competição, visual e musical, permite que as escolas de samba se desloquem no ranking de pontos e por entre os grupos de avaliação, dependendo de sua colocação no desfile (no qual o grupo Especial tem lugar de destaque, podendo haver mobilidade entre os grupos $\mathrm{A}$ e E).

O carnaval é um campo em crescente exploração, promovendo grande movimentação financeira para a cidade do Rio de Janeiro, atraindo, cada vez mais, profissionais de diversas áreas para a produção da festa, evidenciando um mercado profissional em ascensão. Muito se fala também sobre a criatividade destes profissionais, que se caracteriza, cada vez mais, por uma abordagem profissional e especializada e não mais apenas por experiências ou um apuro estético puramente intuitivo.

Com isso, as escolas de samba têm uma demanda cada vez maior por carnavalescos que possuam conhecimento multidisciplinar, capazes de articular questões técnicas, produtivas e socioculturais na elaboração de seus desfiles, visto que a pressão competitiva por resultados positivos sobre as escolas determina o mercado para estes profissionais, 0 
que tem feito as agremiações investirem cada vez mais em profissionais inovadores e qualificados.

\section{Carnavalesco ou um designer temático?}

Dentro da estrutura social de uma escola de samba, o carnavalesco é um personagem de extrema importância para o resultado positivo de um carnaval. Ele é o profissional responsável pela criação, e desenvolvimento, do enredo (tema central) e do roteiro do desfile (sinopse), que conduz às escolhas plástico-visuais nos desfiles das escolas de samba (fantasias, alegorias e adereços), como nos esclarece Luciana Souza (1989):

Sobre o carnavalesco, figura central no barracão, recai as responsabilidades de elaborar a sinopse do enredo para a aprovação pela diretoria, de conceber os carros, fantasias e adereços, de escolher os materiais necessários para sua construção/confecção, bem como fiscalizar o andamento do trabalho e a qualidade dos resultados (SOUZA, 1989, p. 96).

O enredo é o tema que será contado visualmente na avenida e a sinopse é o texto mestre que orienta todo o processo, desde a composição do samba-enredo, à criação e execução das fantasias carnavalescas, ao desenho e desenvolvimento das alegorias e às soluções visuais apresentadas, para que haja um bom entendimento da história durante o desfile da escola. É o carnavalesco quem cria o roteiro do desfile, organizando todos os segmentos da escola de samba, dividindo-os em alas, alegorias e tripés, de acordo com a narrativa e em comum acordo com a direção da agremiação.

Cabe ao carnavalesco realizar extensa pesquisa bibliográfica, visual e de campo, a fim de explorar ao máximo 
as informações sobre o tema e propor uma carnavalização dele, dividindo o desfile em setores para o encadeamento dos fatos da história a ser contada, em suas mais diversas linguagens. Ele deve buscar a coerência entre os diversos elementos e linguagens que comporão o desfile, com objetivo de garantir uma boa compreensão do espetáculo, pelo espectador e pelos jurados, criando uma espécie de narrativa visual. Nesse sentido, o carnavalesco se aproxima da figura de um designer de produtos, pois projeta objetos (alegorias, adereços e fantasias) e, por meio de desenhos e plantas baixas, faz girar uma infinidade de profissionais, como: costureiras, sapateiros, ferreiros, aderecistas, etc. (MAGALHÃES, 1997).

\section{As fantasias carnavalescas como objetos de design}

Após o desenvolvimento da setorização, com a divisão do desfile em segmentos (alas, alegorias e elementos cenográficos), chega o momento de iniciar o projeto plásticovisual. Este artigo foca, especificamente, nos trajes que vestem os brincantes nos desfiles carnavalescos, comumente conhecidos como fantasias. Assim como no projeto de uma coleção de moda, as fantasias carnavalescas possuem etapas de criação e desenvolvimento, de acordo com as informações pesquisadas, gerando diferentes conceitos e culminando na apresentação de resultados, que são os figurinos carnavalescos ou croquis.

As fantasias carnavalescas servem para dar forma à história contada desenvolvida pormenorizada na sinopse e cantada no samba-enredo. Elas devem ter coerência com o tema, desde a concepção até sua realização, e harmonia com o conjunto plástico-visual da escola. Sobre especificamente o 
julgamento de fantasias, observamos no Manual do Julgador da Liga das Escolas de Samba do Rio de Janeiro (LIESA) que as notas variam de 9,0 a 10,0 pontos, devendo considerar: a) concepção (adequação das fantasias ao enredo e a capacidade serem criativas, mas contendo significados relativos ao enredo) e b) realização (formas, materiais e cores, além dos acabamentos, cuidado com a confecção e unidade visual, com relação ao conjunto).

Nos desfiles das escolas de samba, os trajes são geralmente divididos em três grupos:

a) Fantasias de ala - as alas são agrupamentos de brincantes que desfilam no chão, vestidos uniformemente, onde cada ala possui um modelo diferente de fantasia, que deve ser respeitado por todos os integrantes daquele segmento. As alas são formadas por grupos de, aproximadamente, cem componentes e devem mostrar igualdade nas peças, como: calçados, meias, shorts, biquínis, sutiãs, chapéus, etc. Comparativamente ao universo da moda, as fantasias de ala são como as roupas do fast fashion, direcionadas ao público em geral, atendendo a uma grande demanda, com necessidade de reprodução em série e em diversas grades de tamanho $(P, M, G)$;

b) Fantasias de composição - são fantasias intermediárias entre aquelas de ala e às de luxo e que, como a definição dá a entender, compõem os cenários que pontuam e dividem as setorizações dos desfiles, as alegorias. Não há um número preciso e fixo, nesse caso, mas são comumente produzidas em grupos menores do que as alas e são julgadas juntamente ao quesito Alegorias e Adereços (pois compõem uma espécie de quadro vivo) e não pelo 
quesito Fantasias. Em relação ao mercado da moda, seriam como as roupas prêt-a-porter, produzidas em escala industrial, com materiais de melhor qualidade do que as alas, dando um ar mais sofisticado, mas sem a exclusividade da roupa feita sob medida.

c) Fantasias de destaque - são fantasias de luxo e costumam vir em cima das alegorias, ocupando lugares privilegiados (alto, central, frontal) pela visualidade nos carros alegóricos, ou ocupando um espaço entre as alas (menos comum), no chão. É a alta costura do carnaval, pois se trata de um vestuário exclusivo, para um mercado pequeno e seleto, desenvolvido em ateliers especializados neste tipo de vestimenta, utilizando-se de materiais da melhor qualidade que as demais, com bordados preciosos, joias e tecidos exclusivos, além de ser feito sob medida para seu usuário. As fantasias de destaque também são julgadas pelo julgador do quesito Alegorias e Adereços, pelo mesmo motivo das de composição.

O julgamento das fantasias carnavalescas não é simples se consideramos questões como: criatividade, significado e importância para o enredo. Elas têm como objetivo comunicar a ideia desenvolvida ao longo do enredo, visualmente.

Em nosso projeto, analisamos as fantasias porque estas podem ser entendidas como produtos de uma teia social que se assemelham à práxis do design, através de projetos, práticas e processos sistêmicos. Nesse sentido, Cavalcanti (1994, p. 52) afirma que uma fantasia carnavalesca precisa satisfazer às funções de ser usada e apreciada. Mas, é importante enfatizar os diversos elementos que compõem as fantasias, que podem ser classificados como: elementos 
apoiados na cabeça; elementos apoiados nos ombros; elementos apoiados na cintura; elementos apoiados no pescoço, elementos apoiados nos braços e pernas; elementos presos às mãos; elementos presos aos pés (FERREIRA, 1999).

Ao vestir a fantasia carnavalesca, o brincante utiliza-se de elementos que funcionam como próteses, que expandem os limites de seu corpo (tanto vertical, quanto horizontalmente), a fim de se tornar mais visível para o público, devido à distância que existe entre as arquibancadas e a pista de desfile. Assim o superdimensionamento das peças das fantasias visa reforçar o entendimento de seu significado, proporcionando melhor leitura.

\section{O processo em desfile}

Segundo Ferreira (1999, p. 112), o carnavalesco seria "um agente mediador entre as concepções 'modernas' e 'externas' às escolas de samba e aquelas 'tradicionais' e 'internas' destas agremiações". Podemos compreender seu trabalho como interdisciplinar, transitando entre saberes de diversas áreas de criação. Para Sommerman (2006), na interdisciplinaridade reside o fundamento básico da prática do design, sendo este o responsável por uma melhor compreensão da materialidade, de aspectos estéticos, simbólicos, subjetivos, históricos e sociológicos. Neste sentido, concordamos com Oliveira (2014), que entende o fazer carnavalesco como uma "forma particular de design", por congregar saberes e práticas específicas de áreas afins ao campo do design. Sobre o processo de trabalho do carnavalesco, Magalhães (1997) nos diz:

A rotina de trabalho segue mais ou menos o mesmo caminho ano a ano. Primeiro faz-se o enredo, que é distribuído para os compositores. 
Em seguida, desenham-se as fantasias e os carros alegóricos. Em primeiro lugar, executamse trajes piloto para que possam ser multiplicados em tempo hábil [...] Após ter feito o projeto, o carnavalesco tem a chance de ver funcionando os vários setores, e se torna uma espécie de mestre de obras que acompanha a realização de suas ideias (MAGALHÃES, 1997, p. 135).

Assim, a carnavalesca Rosa Magalhães nos esclarece que há certa sistematização nas etapas a serem executadas ao projetar um desfile de carnaval. O ciclo de desenvolvimento dos desfiles das escolas de samba é dividido em etapas como criação do enredo, do projeto plástico-visual; execução de fantasias, alegorias e adereços; ensaios; desfile; desmontagem das fantasias e das alegorias. Esta espécie de calendário, com poucas variações, foi esquematizado por Oliveira (2014) no quadro a seguir:

Figura 1. Ciclo de produção dos desfiles das Escolas de Samba, no grupo Especial.

\begin{tabular}{|c|c|c|}
\hline ETAPA & MESES & AÇĀo \\
\hline 01 & Fevereiro/Março & Desfiles das escolas de samba; \\
\hline 02 & Abril/Maio & $\begin{array}{l}\text { Desmontagem das alegorias; reaproveitamento de } \\
\text { materiais; venda de esculturas para } \\
\text { outras agremiaçōes; }\end{array}$ \\
\hline 03 & Maio/Junho & $\begin{array}{l}\text { Contratação/recontrataçăo de carnavalesco e outros } \\
\text { profissionais, como: mestre de bateria, diretor de } \\
\text { harmonia, etc; eleiçáo de nova diretoria; }\end{array}$ \\
\hline 04 & Junho/Julho & Desenvolvimento do enredo; \\
\hline 05 & Julho/Agosto & $\begin{array}{l}\text { Lançamento do enredo e desenho das fantasias } \\
\text { e alegorias; definiçăo do roteiro do desfile; } \\
\text { entrega da sinopse do enredo para a ala de } \\
\text { compositores do samba-enredo; }\end{array}$ \\
\hline 06 & Agosto/Setembro & $\begin{array}{l}\text { Confecção de peças-piloto ou protótipos a serem } \\
\text { entregues aos diretores de ala para reproduçăo; ensaios } \\
\text { nas quadras, com eliminaçăo dos sambas-enredos } \\
\text { pré-selecionados; inicio de trabalhos para } \\
\text { estruturaçăo de alegorias (ferragem, marcenaria); }\end{array}$ \\
\hline 07 & Outubro & $\begin{array}{l}\text { Desfile de lançamento das principais } \\
\text { fantasias-protótipos; escolha final do samba-enredo; } \\
\text { início de trabalho de decoraçăo das alegorias } \\
\text { (trabalho de bancadas); }\end{array}$ \\
\hline 08 & Novembro/Dezembro & $\begin{array}{l}\text { Confecção das fantasias de ala (nos barracōes), } \\
\text { de composição e destaque (em ateliês externos); } \\
\text { lançamento dos sambas-enredos; }\end{array}$ \\
\hline 09 & Janeiro/Fevereiro & $\begin{array}{l}\text { Finalização de decoração nas alegorias; finalização } \\
\text { e entregas de fantasias e adereços e, finalmente, } \\
\text { preparaçăo para o desfile. }\end{array}$ \\
\hline
\end{tabular}

Fonte: Oliveira (2014, p. 322). 
Observando o quadro acima, podemos entender melhor a estruturação de um desfile de escola de samba - o desfile em processo - e podemos compreender quando e onde começa a produção das fantasias carnavalescas. Assim, para este trabalho, voltamos nossa atenção para o estudo das etapas 04, 05 e 06 do referido quadro.

Para exemplificar a metodologia projetual na concepção de fantasias carnavalescas, apresentamos o desenvolvimento de uma fantasia pelo carnavalesco Severo Luzardo, na escola União da Ilha do Governador, em 2018, abaixo. A reflexão sobre a metodologia empregada na construção de fantasias tem como objetivo indicar ferramentas que possam auxiliar no processo criativo e no direcionamento de critérios, auxiliando o desenvolvimento de projetos e aproximando a prática carnavalesca da prática do design.

\section{Estudo de caso - Figurino carnavalesco "Milho: Grãos de Ouro"}

Severo Luzardo é gaúcho e figurinista desde muito jovem. Realizou muitos carnavais em Uruguaiana/RS (onde tradicionalmente há desfiles de escolas de samba), devido à proximidade de sua família com a agremiação carnavalesca "Os Rouxinóis". Formou-se em Arquitetura e Urbanismo, Publicidade e Propaganda e Artes Plásticas. Posteriormente mudou-se para o Rio de Janeiro, cursou a especialização em Figurino e Carnaval, e foi exercer suas habilidades como figurinista em produções de cinema e televisão, até que surgiu o convite para assumir uma escola de samba, como carnavalesco. Assinou projetos em diversas agremiações carnavalescas, como: Império da Tijuca, Império Serrano e União da Ilha do Governador, entre outras. Assim, percebemos que ele é um profissional híbrido por mesclar sua 
formação acadêmica com atuação profissional, variando linguagens em produtos voltados para o carnaval e o figurino para TV/cinema.

No desenvolvimento do enredo "Brasil bom de boca" (Etapa 04 - Figura 1) para o carnaval de 2018, na União da Ilha do Governador, Severo optou por falar da alimentação inspirado em um livro homônimo de Raul Lody (2008), que lança um olhar antropológico sobre a culinária brasileira, cuja origem só seria possível graças ao caldeamento das etnias formadoras do Brasil e à variedade de condições naturais de nosso vasto território. Ao consultarmos a roteirização proposta pelo carnavalesco para o referido desfile, encontramos a seguinte divisão: a) $1^{0}$ setor: Dá uma provadinha...; b) 20 setor: Sabores da Terra; c) 30 setor: Procure uma nega baiana que saiba mexer...; d) 40 setor: Super safra bronzeada mostra o seu valor... e, finalmente, e) $5^{\circ}$ setor: Saindo do armário da cozinha (ABRE-ALAS, 2018, segunda-feira, p. 128-132).

O enredo "Brasil bom de boca" trata da culinária brasileira como consequência da miscigenação do povo brasileiro. Severo Luzardo inicia o enredo contando sobre influência que veio de além-mar, dos portugueses (10 setor), passa por nossas raízes indígenas ( ${ }^{\circ}$ setor), a herança culinária africana (30 setor), grifa a importância do agronegócio brasileiro ( $4^{\circ}$ setor) e finaliza o desfile exaltando as riquezas e variedades da culinária brasileira, através da valorização dos chefes de cozinha, que são os responsáveis por criar diversas iguarias com uma assinatura brasileira e contemporânea ( $5^{\circ}$ setor).

Assim como os produtos de moda, a criação das fantasias carnavalescas envolvem etapas de criação que podemos classificar como: a) planejamento; b) geração de alternativas; c) avaliação e detalhamento; d) produção (SANCHES In: 
PIRES, p. 291). Por isso, é importante demonstrar como o processo se dá no universo carnavalesco.

A sinopse e a roteirização do desfile traduzem uma série de informações, de ordem abstrata e/ou concretas, seguidas de análise e síntese. Assim como no desenvolvimento dos produtos de moda, trata-se de uma fase de planejamento onde há a coleta de informações que se desenvolverão no projeto plástico-visual da escola de samba. A partir de uma análise minuciosa do tema, é possível a construção do texto guia e a tomada de decisões que delimitam as características necessárias ao projeto de fantasias, definindo seu direcionamento estético e suas técnicas de construção. A fim de contextualizar a importância do planejamento das fantasias carnavalescas dentro do desfile, abaixo extraímos parte da roteirização (Figura 03), contida no livro Abre-Alas (2018), onde podemos identificar a fantasia "Milho: Grãos de Ouro" no segundo setor da escola (na ala 04), em arranjo com as temáticas das fantasias que a precedem e sucedem: 
Figura 3. Parte da roteirização do desfile.

Abre-Alas - G.RE.S. União da Tha do Governador - Carnanal/2018

\section{ROTEIRO DO DESFILE}

Comissão de Frente
O BANQUETE!

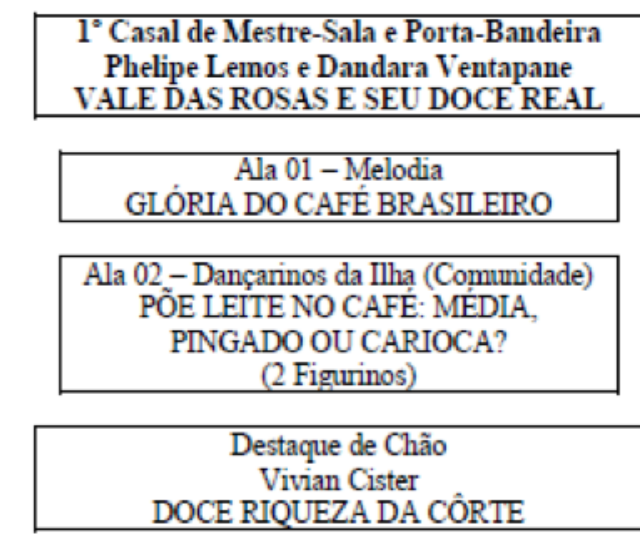

Ala 03 - Batuke de Batom (Comunidade) REQUINTE DO AÇÚCAR

\begin{tabular}{|c|}
\hline $\begin{array}{c}\text { Abre-Alas - Alegoria } 01 \\
\text { CARAVELAS A BAILAR NO MAR }\end{array}$ \\
\hline $\begin{array}{c}\text { Ala 04 - Comunidade } \\
\text { MILHO: GRÃOS DE OURO }\end{array}$ \\
\hline $\begin{array}{l}\text { Ala 05 - Sou Mais Minha Ilha } \\
\text { (Commidade) } \\
\text { ABACAXI: FRUTA CHEIROSA }\end{array}$ \\
\hline $\begin{array}{l}\text { Ala } 06 \text { - Beleza Pura (Comunidade) } \\
\text { CAJUS DE SABORES INOCENTES }\end{array}$ \\
\hline $\begin{array}{c}\text { Ala } 07 \text { - Comunidade } \\
\text { PIMENTA, A ALEGRIA DO GOSTO }\end{array}$ \\
\hline
\end{tabular}

Fonte: ABRE-ALAS, 2018, segunda-feira.

No planejamento do projeto (Etapa 04 - Figura 1), o conceito central de cada setor é traduzido em referências visuais, captadas a partir do tema, servindo como fio condutor para o desenvolvimento das fantasias de ala daquele setor. Comumente, os carnavalescos se utilizam da ferramenta de briefing visual, construindo painéis de imagens ou colagens inspiracionais com representações que servem de referencial estético-conceitual para a criação dos figurinos carnavalescos. 
A partir de um prancha de referências, é feita uma colagem com imagens, ícones e símbolos que serão apresentados em cada um dos figurinos carnavalescos.

A Figura 4 é parte do projeto de fantasia da ala "Milho: Grãos de Ouro", desenvolvida por Severo, que busca a influência dos povos naturais do Brasil, fazendo referência à origem indígena, por meio do alimento milho e sua importância em nossa culinária.

Figura 4. Figurino carnavalesco Milho: Grãos de Ouro.

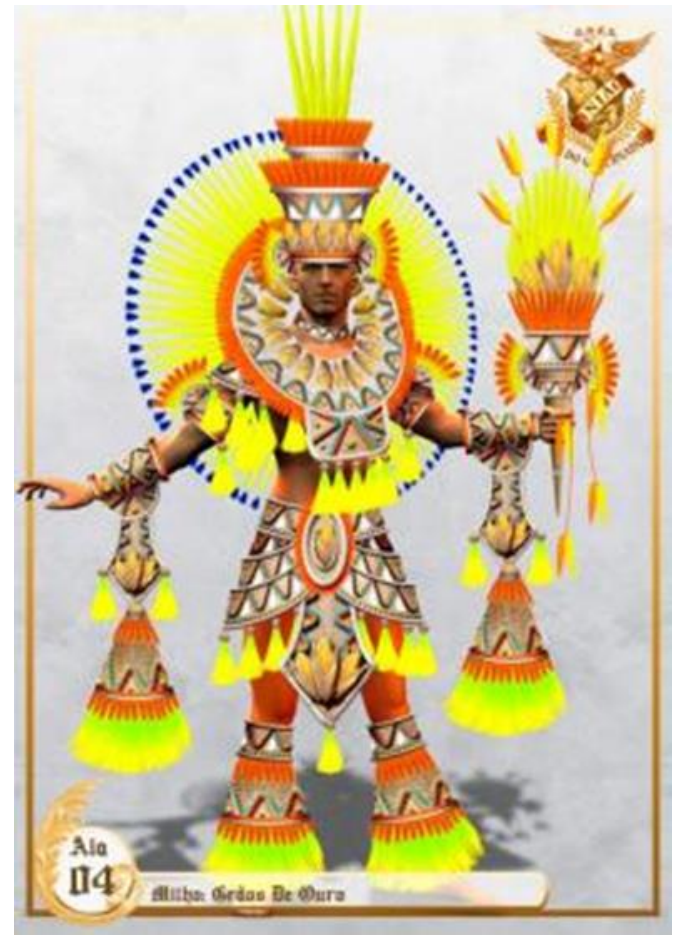

Fonte: Severo Luzardo (2018).

Antes da apresentação do figurino carnavalesco finalizado (Figura 4) há a fase de geração de alternativas (Etapa 05 Figura 1), onde são suscitadas possibilidades através do estudo de silhuetas e de possíveis usos de materiais.

A geração de alternativas é um dos principais pontos do projeto carnavalesco, pois nesta etapa ocorre a transformação das necessidades do enredo, e da temática das 
fantasias, em uma nova configuração volumétrica e estética. Nos projetos de design, por exemplo, a geração de alternativas ocupa importante lugar nas metodologias de projeto que, assim como no carnaval, localiza-se no período intermediário do processo de produção do objeto. Nesta fase, são utilizadas técnicas de colagem e ferramentas de desenho (manual ou digital) que objetivam auxiliar o carnavalesco expressar as influências que ele deseja apresentar nas fantasias, bem como suas ideias criativas e inovações materiais, compondo assim um figurino rico em camadas de referenciais simbólicos e definições precisas de materiais, bem como suas possíveis tecnologias construtivas.

No figurino carnavalesco "Milho: Grãos de Ouro" podemos notar que a referência aos povos indígenas se dá pelo grande planejamento do uso das penas (penas de pato e faisão), que estão presentes no cocar (apoiado na cabeça), no costeiro (apoiado nos ombros), nos pingentes (espalhados pela fantasia), no adereço de mão e nos elementos apoiados nos punhos, cintura e pernas. Acrescente-se a isso, o fato do figurino não possuir peças de roupa-base, deixando partes do corpo à mostra, como costume indígena. Ademais, é patente os elementos geométricos que decoram boa parte do figurino, imitando pinturas corporais que, no caso dos indígenas é muito comum em rituais e festividades.

Já a referência ao milho se dá no uso de espigas de milho pontualmente aplicadas no adereço de mão, na gola, nos punhos, na cabeça e no saiote. Podemos notar, ainda, a intenção de usar materiais rústicos como base (juta), presente nos punhos, base da gola, cocar, adereço de mão, etc. Como o figurino se refere ao milho como sendo um grão de ouro, o carnavalesco optou por usar tons de laranja e amarelos vibrantes, que são tonalidades do espectro dourado, 
utilizando-os nas penas, que se tornam as partes mais luminosas deste figurino.

O termo design está diretamente relacionado ao processo de configuração de produtos, que podem ser objetos de uso e/ou sistemas de informação e comunicação. E o que se faz no projeto carnavalesco senão o fato de se pensar e criar objetos de uso e manipular sistemas de informação e comunicação? No carnaval, assim como o design de produto, é constituído por projeto e produção, sendo estes orientados a um cenário futuro, propondo objetos que irão existir. Este fato também ocorre no design de moda, onde as coleções são pensadas e projetadas com quase um ano de antecedência de seu lançamento. Como nos mostra a Figura 01, os desfiles das escolas de samba começam a ser pensados e projetados cerca de nove meses antes do carnaval.

Após a elaboração e desenho do figurino carnavalesco, inicia-se 0 processo de prototipagem das fantasias carnavalescas (Etapa 06 - Figura 1). Para tal é construída uma fantasia protótipo (Figura 5), que serve como base norteadora para a sua posterior reprodução em série. 
Figura 5. Fantasia carnavalesca Milho: grão de ouro.

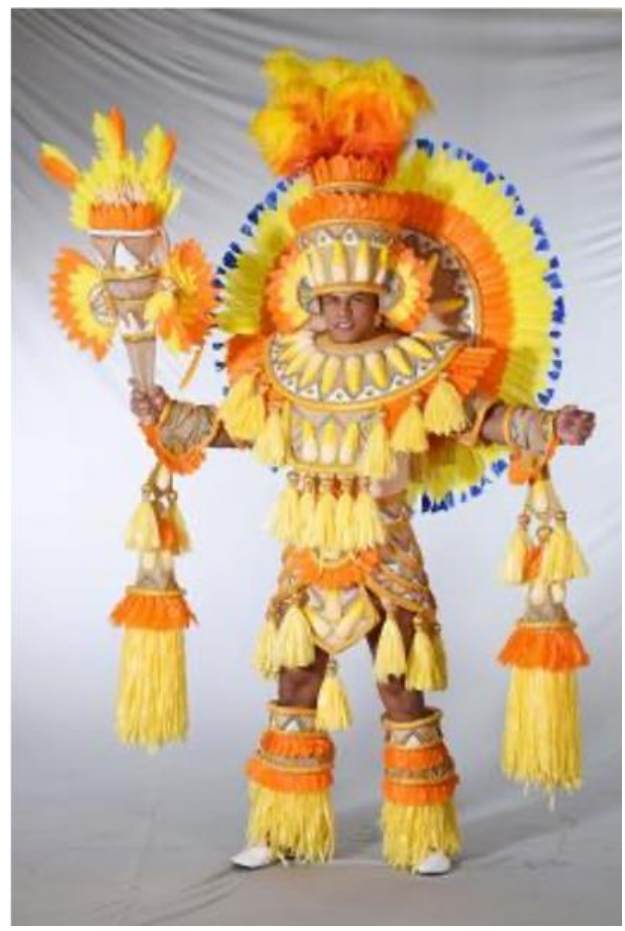

Fonte: Severo Luzardo (2018).

A partir da fantasia protótipo é possível fazer a avaliação e o detalhamento do projeto da fantasia carnavalesca. É nesta etapa onde são desenvolvidas as modelagens das partes que compõem a fantasia (tecidos, adereços e calçados), bem como a adaptação dos materiais, cores, texturas, volumetria e das proporções entre as partes. Assim como no design de moda, nesta fase do projeto, é importante que o carnavalesco saiba coordenar uma equipe de modelistas, costureiras, aderecistas e sapateiros, pois estes parceiros profissionais são essenciais para a construção de uma boa fantasia, que atenda a padrões estéticos e de conforto. Suas expertises profissionais serão fundamentais para a materialização do desenho, exprimindo da melhor forma as ideias e conceitos pretendidos no projeto da fantasia carnavalesco. Juntamente a estas avaliações é feita uma ficha técnica onde é possível detalhar todos os itens que compõem a fantasia, suas 
quantidades e especificidades, permitindo assim a precificação da ala e a especificação da quantidade de material necessário para a compra, tornando esta etapa também de extrema importância para o planejamento financeiro da escola de samba. É, ainda, nessa fase (Etapa 06 - Figura 1) que é feita uma pesquisa dos materiais disponíveis no mercado para que a equipe do carnavalesco possa ter noção do que pode ser usado nos protótipos e sua posterior reprodução.

A fantasia deve se relacionar intrinsicamente com suas matérias-primas e processos construtivos. Assim, é importante que o carnavalesco conheça os materiais, maquinários e técnicas construtivas para materializar aquele figurino carnavalesco. Os tecidos escolhidos, a modelagem, os aviamentos e os adereços, nesta fase da fantasia, podem sofrer alterações em relação ao figurino, em função da ergonomia e para o conforto do brincante.

Nesta fantasia protótipo podemos confirmar algumas indicações do que Severo planejava no figurino carnavalesco, bem como algumas adaptações no que era planejado, mas sempre em conformidade com a proposta original. Confirmamos o uso das penas de pato, nas cores laranja e amarela, aplicadas a diversos elementos que compõe a fantasia (cocar, gola, punhos e adereço de mão). No figurino (Figura 4) havia a intenção de uso de uma pena, que se assemelha à pena de faisão, no costeiro e no topo do cocar, que na materialização não foi utilizada, sendo substituída por pena de pato e plumas, respectivamente. Podemos notar ainda que não foram usadas penas de pato nos elementos apoiados nos punhos e pernas, aqui substituídos por ráfia plástica, de cores amarela e laranja. Ratificamos, ainda, o uso da juta como tecido de base, que visa dar aspecto rústico à fantasia e o uso das espigas de milho, que justificam o tema 
central da fantasia, aqui materializadas através de placas de EVA, fabricadas pelo processo de vacuum forming e com pintura de arte aplicada. Podemos notar ainda que houve adaptação no formato (silhueta) dos pingentes, bem como adaptações de proporções à escala humana que, na Figura 4 era mais alongada e na Figura 5 ficou mais achatada.

A prototipagem destina-se, ainda, a evitar eventuais diferenças entre as fantasias de mesma ala, permitindo a unidade visual pela uniformidade dos elementos estéticos e a racionalidade dos processos de trabalho. Finalizado esta sistematização, o carnavalesco deve, ainda, coordenar a execução das diferentes partes do projeto, distribuindo as tarefas a serem desenvolvidas de acordo com as necessidades específicas de cada projeto, acompanhando a realização das suas ideias, conforme citação a seguir:

Se a concepção do enredo, fantasias e alegorias do desfile é a princípio atributo de um indivíduo, o carnavalesco, a sua execução explicita, como veremos, o caráter coletivo do processo. Essa percepção, extensiva à produção do desfile como um todo, é especialmente clara no exame da confecção das alegorias no barracão (CAVALCANTI, 1994, p. 133).

Ao tratarmos do caráter coletivo da profissão do carnavalesco, podemos ressaltar que muito embora ele seja a figura central do projeto plástico-visual a realização prescinde de outros profissionais para se constituir. Ademais, cabe aqui traçar um paralelo com a fala de Moraes (2007), no que tange a concepção, no caso dos designers:

Ao longo do tempo o design tem sido entendido segundo três tipos distintos de prática e conhecimento. No primeiro o design é visto como atividade artística, em que é valorizado no profissional o seu compromisso como artífice, com a fruição do uso. No segundo entende-se o design como um invento, um planejamento em 
que o designer tem compromisso prioritário com a produtividade do processo de fabricação e com a atualização tecnológica. Finalmente, no terceiro, aparece o design como coordenação, onde o designer tem a função de integrar os aportes de diferentes especialistas, desde a especificação da matéria prima, passando pela produção à utilização e ao destino final do produto. Neste caso a interdisciplinaridade é a tônica (MORAES In: NIEMEYER, 2007, p. 12).

Com a ficha técnica pronta e preenchida, passa-se à produção seriada das fantasias carnavalescas (Etapa 08 Figura 1), processo internamente chamado de "reprodução". Nesta fase, a fantasia é reproduzida conforme a fantasia protótipo e possíveis mudanças são corrigidas e/ou adequadas. Durante a reprodução, normalmente, não há a realização de mais de um protótipo de fantasia.

Os desfiles das escolas de samba pautam-se essencialmente sobre duas palavras-chaves: inovação e criatividade. Uma série de soluções, maquinários e produtos são concebidos para o carnaval, intensificando as esferas econômicas, produtivas e tecnológicas do espetáculo. O carnaval estabelece relações sociais e culturais que são associadas à indústria, ao usuário e ao mercado consumidor e o mesmo acontece com as diversas áreas do campo do design.

O design é um campo do conhecimento e da cultura que funciona a partir da criação e do desenvolvimento de um universo criativo. Criar e produzir um desfile de uma escola de samba é agir neste universo inventivo: no sentido material, imaterial e simbólico. Os carnavalescos, em sua atividade profissional, devem interpretar e filtrar as informações do projeto, as transformando em objetos atrativos, seguindo parâmetros técnicos, econômicos, produtivos, culturais e sociais. Assim, a concepção de um desfile de escola de samba pode ser mais promissora aliada a princípios projetuais de 
design, devido a forma interdisciplinar desta área. Esta visão deve ser percebido pelo público, pela crítica e comissão julgadora.

\section{Considerações finais}

Através da análise do processo criativo do carnavalesco Severo Luzardo, na criação da fantasia carnavalesca "Milho: Grãos de Ouro", podemos constatar que o projeto de uma fantasia é uma atividade sistemática, que engloba o uso de diferentes metodologias, de diversos processos produtivos e envolve profissionais de diferentes saberes. $O$ processo criativo de uma fantasia carnavalesca reafirma a função do carnavalesco para além da aptidão técnica do desenho, configurando-se um gestor de projetos e profissionais em torno do mesmo.

Vale ressaltar, ainda, a complexidade em desenvolver o tema (enredo) em uma série de fantasias, alegorias e adereços que comuniquem uma mensagem necessária ao entendimento do público e dos jurados, vistas à distância e sem legendas. Devido a este fato, o bom uso de materiais, formas, simbologias e criatividade são itens de extrema importância, já que os desfiles são comparativos e avaliados. Ou seja, espera-se certa dose de ineditismo ou uma exploração de materiais inusitados, com aplicações diferenciadas, a fim de surpreender com soluções que são de ordem estética e simbólica e que surpreendam positivamente nos desfiles, pois as fantasias precisam se comunicar visualmente.

Este é um desafio experimentado a cada ano pelos carnavalescos que acrescentam ao seu trabalho uma espécie de sintaxe visual, pela proposição de seu trabalho, ao longo de sua trajetória profissional. Neste sentido, alguns 
carnavalescos desenvolvem verdadeiras assinaturas estéticas em função de suas práxis.

As questões observadas no exemplo aqui apresentado nos fazem enxergar o carnavalesco como uma espécie de designer de produto que atravessa variados saberes, com domínio de: cores, materiais, formas, confecção, calçados, etc. Só para ficar no campo da fantasia, os conhecimentos técnicos devem ser acompanhados de conhecimentos de história, cultura geral, escultura e tudo o quanto presta-se a colocar, literalmente, um desfile na rua.

Através deste estudo, podemos concluir que os carnavalescos e os designers possuem em suas práticas profissionais processos criativos e produtivos que se assemelham, como o uso da sensibilidade, de conceitos, de tendências, de técnicas, de conhecimento técnico-científico adquiridos ao longo de suas formações e carreiras profissionais, bem como organização, observação e uso de metodologias para o desenvolvimento de seus projetos.

\section{Referências}

CAVALCANTI, Maria Laura Viveiros De Castro. Carnaval carioca: dos bastidores ao desfile. Rio de Janeiro: FUNARTE/UFRJ, 1994. FERREIRA, Felipe. O livro de ouro do carnaval brasileiro. Rio de Janeiro: Ediouro, 2004.

FERREIRA, Felipe. O marquês e o jegue: estudo da fantasia para escolas de samba. Rio de Janeiro: Altos do Glória, 1999.

Manual do Julgador da Liga das Escolas de Samba do Rio de Janeiro (LIESA). Disponível em: http://liesa.globo.com/material/materia2019/publicacoesliesa/ MANUALDOJULGADOR/Manual\%20do\%20Julgador\%20\%20Carnaval\%202019.pdf. Acesso em 13 maio 2019. LODY, Raul. Brasil bom de boca. São Paulo: Ed. Senac, 2008. MAGALHÃES, Rosa Lucia Benedetti. Fazendo carnaval: The making of carnival. Rio de Janeiro: Nova Aguilar, 1997.

NIEMEYER, Lucy. Design no Brasil: origem e instalação. Rio de Janeiro: 2AB, 2007. 
OLIVEIRA, Madson. "As fantasias para escola de samba". In: VIANA, Fausto; BASSI, Carolina (orgs.). Traje de cena, traje de folguedo. São Paulo: Estação das Letras e Cores, 2014.

PIRES, Dorotéia. Design de Moda: olhares diversos. Barueri/SP: Estação das Letras e Cores Editora, 2008.

SOMMERMAN, Américo. Inter ou transdisciplinaridade?: da fragmentação disciplinar ao novo diálogo entre os saberes. São Paulo: Paullus, 2006.

SOUZA, Luciana Barbosa de. Desfile em processo: um estudo da produção das alegorias e fantasias para o desfile das escolas de samba do Rio de Janeiro. Rio de Janeiro: PUC - Rio (Dissertação de Mestrado em Design), 2001.

UNIÃO da Ilha do Governador. Livro Abre Alas 2018. Disponível em: $\quad$ https://liesa.globo.com/2019/por/03carnaval/abrealas/index.html. Acesso em: 2 mar. 2018. 